\title{
Role of Counselling in HIV Positive Status Disclosure among Sexual Partners in Kibera Informal Settlement, Nairobi; Kenya
}

\author{
Fr. Abok Michael, Dr. Dennis Nyongesa Wamalwa
}

\begin{abstract}
This study clearly revealed that experience of HIV status disclosure among sexual partnersis generally painful and an immense challenge for the people living with HIV/ AIDS. Considering the danger of infection and re-infections, there is an urgent need to address these challenges and provide the necessary emotional support. Silence is highly dangerous in this situation, and, as our practice has shown again and again, too often lack of HIV status disclosure ends in death and in spreading the virus. Stigma, discrimination, disempowerment, poverty and, gender inequality cripple and affect the infected people's coping mechanisms. Literature, previous research and current findings are all in agreement on this topic.Counselling was found to play a great role in HIV positive status disclosure among sexual partners in Kibera informal settlement in Nairobi, Kenya.

Index Terms - HIV/ AIDS, Status, Disclosure.
\end{abstract}

\section{INTRODUCTION}

Highlight Bor et al, (1991) commenting on the impact of the virus, both physical and psychological, on the infected person says it is obvious and undeniable. It's true that the impact of HIV/AIDS on the relationships of the infected persons, family, and significant others on the responses and adaptation of the infected person to the virus, is often overlooked in the literature.

In medical set-ups providing HIV/AIDS care, information booklets and IEC material should be provided. This was taken seriously by MSF-Belgium in its implementation's sides in Kibera informal settlements. Unfortunately, in the area of HIV counselling, therapists have often found that people's beliefs are often a major block to their adjustment. A common example of the way these beliefs inhibit people's adjustment is their reactions to an HIV positive diagnosis. A couple I had done diagnostic counseling and testing within one of the health centers reacted....

“...This can't be true, it can't be me, look unless I got it from the Bible, am a pastor, look at my wife, she is faithful and she was the first woman I had in bed, what are you telling us..."

The prevalent view of the community, although diminishing with increased public knowledge and awareness of HIV/AIDS remains a challenge as De Rosa, and Marks,

\footnotetext{
Fr. Abok Michael, MACandidate,Institute of Security Studies, Justice and Ethics (ISSJE) Mt Kenya University, Kampala Campus; Uganda

Dr. Dennis Nyongesa Wamalwa PhD, Lecturer / Consultant; Ph.D.,Departmentof Peace and Conflict Studies, MasindeMuliro Universityof ScienceandTechnology,Kenya
}

(1998) puts it: "HIV positive" equals “AIDS" equals "imminent death". This belief is often held by those diagnosed with HIV, and their families, and often results in an emotional paralysis and inability to make plans for the future. It is only when these beliefs are challenged and start to change that they begin living with HIV and rebuild a future self. This will only happen if the counsellor has a good relationship with the client in the counselling session. " $A$ non-blaming, respectful counselling model which seeks to empower clients to feel in control of their lives and futures may assist people living with HIV/AIDS to live more meaningful lives in general and with their significant others" asserts Stynes (1996)

\section{STATEMENT OF THE PROBLEM}

Staff who worked in MSF- Belgium HIV clinics in Kibera informal settlements, report that HIV-status-disclosure among sexual partners was a major challenge in the effort to fight the spreading of HIV/AIDS, as secrecy led to a lack of adherence to medication.

The benefits of disclosure, however, were observed as being highly therapeutic for the patients. This research therefore sought to explore the role of counselling in disclosure among HIV positive sexual partners in Kibera informal settlement. It examined the factors promoting non-disclosure to spouses versus factors enhancing disclosure.

\section{RESEARCH METHODOLOGY AND DESIGN}

In this study qualitative research methods were used to conduct a cross sectional exploration on the role of counselling in disclosure among HIV positive sexual partners living in Kibera informal settlement, Nairobi Kenya. The cross-sectional study design was used in obtaining the overall picture as it stood out at the time of the study. Babbie (1989) commenting on this design says "they are designed to study some phenomenon by taking a cross section of it at a time".

A qualitative approach was chosen as none had been previously conducted in the area and topic of research.

A qualitative approach allowed for an in-depth exploration of participant's views and experiences of the research topic. Qualitative research methods have been recommended for use in public health research, 'to study and explain the economic, political, social and cultural factors that influence health and disease in more depth than is possible through a survey or other quantitative methods (Baum, F.1998, p.149). 


\section{A. Location of the Study}

The study took place in Kibera informal settlement; with an estimated population of between 600,000 to $1,000,000$ at the time of research. The study respondents were residents of Kisumu Ndogo one of the twelve villages where one of the MSF-Belgium Kibera South Health Centre (KSHC) clinic was located. The population size of the study base was estimated at 83, 000 population. The target population were clients of the MSF-B KSHC in this village, who were HIV-positive and who were attendees of a Post Test Club (PTC) situated in Kisumu Ndogo village. The total population comprised of approximately 6 PTCs each with up to 15 members (target population of about 90 , most of whom attended the MSF-B clinics). This was out of the twenty PTCs in Kibera with the capacity of 300 members.

\section{B. Target Population}

The study subjects were people from the target population who had lived in Kibera for at least 12 months, who had been married or had sexual partners for at least 12 months, had tested HIV-positive for the first time more than 6 months prior to the study, and who had disclosed their HIV-positive status to their partners.

\section{Determination of the Study Sample \& Size}

It was not possible to establish a sampling frame for the target population due to the difficulty of identifying and locating members of the target population in the community. Members of PTCs were disclosed or undisclosed about both their HIV status and their membership of a PTC, hence rendering the establishment of a sampling frame difficult. In the absence of a sampling frame, snowball and purposive sampling methods were used to identify study subjects Baum, F. (1998) \&Antelman, G. et al. (2001)

Snowball sampling which uses word of mouth and informal and formal networks to identify potential key informants (study subjects), in the absence of a clear sampling frame was used.

This involved asking each study subject identified, to recommend or help find other potential study subjects. Purposive sampling aims to identify study subjects with knowledge and experience of the underlying issues of the research topic Bowling (1999). Snowball and purposive sampling, both aim to identify and recruit study subjects who are likely to 'provide rich data and enable a detailed study' Baum (1998)

The aim was to recruit twelve study subjects among the target population, 6 of whom had disclosed their HIV-positive status to their sexual partners. While any person can join a post -test club (PTC), a criterion for being a 'leader' of a PTC is disclosure to a sexual partner. In the village of Kisumu Ndogo, where 6 PTCs were based, the leaders of these 6 PTCs were purposively sampled and invited to participate in the study. These PTC leaders all conduct health talks in the MSF-B Kibera clinics and hence were easily identifiable to the researcher.
The leaders (disclosed status to sexual partners) of the 6 PTC in Kisumu Ndogo were approached by the researcher while they were in the clinics to deliver health talks, and were explained the purpose of the research and were requested to participate. These potential study subjects who were disclosed about their status were asked to attend a meeting with the researcher to be explained the purpose of the research in detail, and to request their assistance in identifying members of their PTCs who disclosed about their HIV status and who they thought would be willing to participate in the study. The researcher contacted identified clients through the phone to explain the study and informally request their participation in the study. All of the study subjects were then provided with an information letter about the study, the proposed questions to be asked of them and a consent form was signed.

\section{Data Collection Instruments}

The data collection method chosen for the study was indepth interviews for focus groups of post -test club leaders who were disclosed about their status to their sexual partners.

The focus group with study subjects who had disclosed their status to their sexual partners was conducted through an in-depth interview schedule questionnaire. Discussion generally moved from issues of lesser to greater complexity, as the interview progressed. Interviews were conducted via face to face in the counselling room at MSF- Belgium Kibera project.

\section{FINDINGS}

The study's objective was to explore the role of counseling in disclosure among HIV positive sexual partners in Kibera informal settlement in Kenya. Respondents were asked the following question; Did you go through any counselling session? If yes, what was your experience of counselling in HIV status disclosure to your spouse/ sexual partner?

All the key informants admitted that they went through counselling. The disclosed group appreciated good counselling support. Some of their sentiments were as follows;

'....So I believe actually without counselling it would have been difficult for me to disclose to my partner actually it a vital tool ....' (Focus group discussion (FGD C2-RO))

'.... Counselling to me was a pillar of support because once I testes, I really didn't know how to go about it..........they gave me the skills to use in the disclosure and also how to take care of my own life so I would say without counselling disclosure would be very difficult if not next to impossible...' (FGD C3-JI)

Participants responded that in their experience, counselling enhances disclosure and adherence, relationships among partners

, It's a tool that helps in accepting and copping with HIV status, it addresses fears and promotes Prevention of Mother to Child Transmission

'....it is also a key to adherence because the spouses will now be open to another and there will no longer be hiding 
when taking drugs and in fact one will act as treatment assistant and a buddy to another... '. (FGD C1-EK)

'.... think in my case it is a tool or a kit which can go away with fear in your lives and will destroy the fear and know how to overcome the fear...' (FGD C5-BA)

'....with Counselling in HIV amongst spouse helps in promoting the program to prevent mother to child transmission that we can get children who are HIV free and have generation that is HIV free.... '( FGD C1-EL)

\section{SUMMARY}

The supporting factors for disclosing included the need to get partners tested through some kind of assistance or collusion with HCW, husband's illness as opportunity for disclosing, and the need for Counsellor support.The level of education was positively associated with disclosure since the disclosed group had a higher level of education at least past post-secondary and colleges, some are working. On the other hand, the undisclosed group never went beyond primary school. Positive outcome of HIV status disclosure was commonly appreciated. Increased support, acceptance, decreased anxiety and strengthening the relationship. However, the negative outcome was also described, namely abandonment, rejection, anger, blame violence. De Rosa, and Marks (1998), concurs and asserts that ddisclosure leads to increased HIV preventive behaviors including safe sex, prevention of mother to child transmission, and opportunities to plan for the future coupled with improved access to necessary medical treatment and care. Counselling was generally reported as a very important tool in HIV status disclosure.

\section{CONCLUSION AND RECOMMENDATIONS}

This study clearly reveals that the role of counseling in disclosure among HIV positive status among sexual partners in Kibera informal settlement in Kenya are generally painful and an immense challenge for the people concerned. Considering the danger of infection and re-infection, there is an urgent need to address these challenges and provide the necessary emotional support. Silence is highly dangerous in this situation, and, as my practice has shown again and again, too often ends in death and in spreading the fatal disease. Stigma, discrimination, disempowerment, poverty and, for women, gender inequality cripple and affect the infected people's coping mechanisms. Literature, previous research and current findings are all in agreement on this topic.

It is therefore recommended that counselling strategies need to be culturally appropriate to the target audience hence there is need for Counsellor / Client initiated disclosers. Similarly, ongoing counselling and HIV support groups (PTCs) may present a key opportunity for discussing fears and concerns around disclosure as well as sharing disclosure strategies amongst pee

\section{REFERENCES}

[1] Antelman, G. et al. (2001). Predictors of HIV-1 status disclosure: A prospective study among HIV-infected pregnant women in Dar es Salaam, Tanzania. Aids, 15:1865-1874

[2] Baum, F. (1998). The New Public Health: an Australian perspective. (1st edition). Melbourne: Oxford University Press.

[3] Babbie, E. (1989). The practice of Social research. California, Wadesworth Publishing Company

[4] Bowling, A. (1999) Research Methods in Health. (3rd Edition). Buckingham, Philadelphia: Open University Press.

[5] Bor, R., and Elford, J. (1994). The family and HIV: London: Cassell.

[6] De Rosa, C., and Marks, G. (1998) Preventive counselling of HIVpositive men and self- disclosure of status to se partners: new opportunities for prevention. Health Psychology, 17: 224-31.

[7] Heppner, P. Paul, Kivlighan, D. Jr., \& Wamplod, B., (1992). Research Designs in Counselling. Pacific Grove, California: Brooks/Cole.

[8] Stynes, 1996. Impacts of the Grand Traverse Resort on the local community. In Issues in Tourism. L. Harrison and W. Husbands (eds). New York: John Wiley.

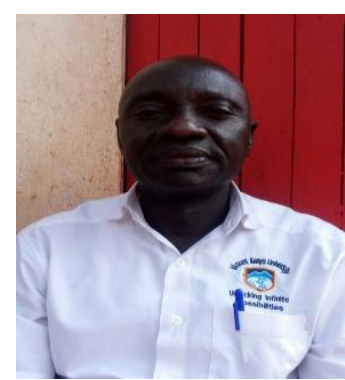

Fr. Michael Abok is a Catholic priest in the Institute of Apostles of Jesus with its Genera late (Headquarters) at Karen, Nairobi, Kenya. He holds a diploma in philosophy and theology from Apostles of Jesus Scholasticate, Langata, Nairobi, and a diploma in law from the law development Centre, Kampala, Uganda. He has a bachelor of sacred theology from Urbaniana University, Rome. Besides, $\mathrm{He}$ has a post-graduate diploma in education from Kabale University, and a Post-Graduate Diploma in Public Policy and Governance from Uganda Management Institute Kampala. At present he is pursuing a Master of Arts Degree in governance and ethics at Mount Kenya University Nairobi- Kenya. He has served as a church minister in many places and positions including but not limited in Isiolo Vicariate as a deacon in Uganda, he served in many parishes and seminaries. He was a rector in Apostles of Jesus Seminary Moroto, a Spiritual Director at St. John the evangelist Seminary in Kasese diocese. He was also teacher at Aboke Minor Seminary in Lira diocese coupled with being a Chaplain at St. Theresa Girls Secondary school in Kasese and Chaplain at Ndejje University Kampala Campus. He also served as parish priest at Lira Diocese and Nebbi diocese. Currently, he is based at the Apostles of Jesus Regional Headquarters at Mazzoldi House, Kampala Uganda.

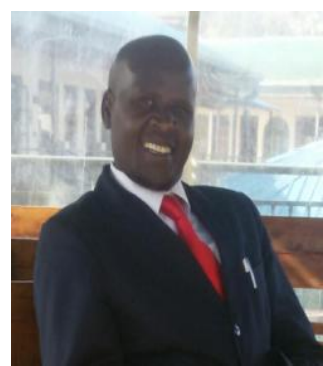

Dr. Dennis N. Wamalwa is a Mental Health and Psychosocial wellbeing consultant, lecture/ trainer and researcher with various international, national and local NGOs, cooperates, government and health institutions for over 18 years. Registered member of Kenya Counsellors and Psychologists Association (Reg. No 0038/06 Dr. Wamalwa holds a $\mathrm{PhD}$ in Peace and Conflict Studies from Masinde Muliro University of Science and Technology (MMUST) Kenya and a Masters of Arts in Counselling Studies, from The University of Manchester, (UK)coupled with numerous professional credentials. He has chaired presentation /defense panels and supervised of 20 postgraduate students' projects and theses to completion from various universities presented papers in national and international conferences and published over 15 research papers in refereed journals with high impact factor. 